\title{
MMW-HOTLINE
}

Leser der MMW können sich mit allen Fragen zur Abrechnung und Praxisführung an Helmut Walbert, Facharzt für Allgemeinmedizin, Würzburg, wenden. Sie erreichen inn jeden Donnerstag von 13 bis 15 Uhr unter der kostenlosen Rufnummer (0800) 2379830 oder per E-Mail: w@lbert.info.

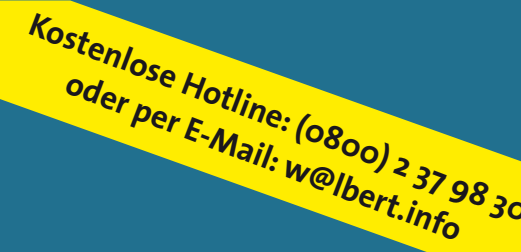

(a)

Influenza

\section{Wie rechnet man den Grippeschnelltest ab?}

Dr. R. L., Hausarzt-Internist, KV Bayern Ich mache bei Grippeerkrankungen einen qualitativen Grippeschnelltest in der Praxis. Wie kann ich diesen abrechnen? Antwort: Im Bereich der gesetzlichen Krankenversicherung (GKV) gibt es keine Abrechnungsmöglichkeit, da ein solcher Test nach \$12, SGB V als nicht notwendig erachtet wird und daher unwirtschaftlich ist. In der letzten Saison war der Test zur Identifizierung der Schweinegrippe abrechnungsfähig. Diese Leistung ist Mitte des Jahres ausgelaufen.

Haben Sie jetzt einen Patienten mit Grippesymptomatik und wollen die Diagnose Typ A oder B absichern, um spezifische antivirale Medikamente einsetzen zu können, dann ist diese Diagnostik im GKV-Bereich eine Individuelle Gesundheitsleistung
(IGeL). Dies gilt auch für Postbeamte oder ehemalige Bundesbahnbeamte.

Die Leistung wird in diesen Fällen nach GOÄ abgerechnet. Dies gilt selbstverständlich auch für Privatpatienten: Sie liquidieren die Beratungsleistung, die in jedem Fall anfällt, nach GOP 1, € 10,72, 2,3-fach. Die Mitteilung: Test positiv oder negativ ist eine ärztliche Beratungsleistung! Die Entnahme von Abstrichmaterial aus $\mathrm{Na}$ sen- und/oder Rachenraum wird nach GOP $298, € 5,36,2,3$-fach abgerechnet. Da es in der überalterten GOÄ keine Gebührenordnungsposition für den Influenzaschnelltest gibt, müssen sie nach $§ 6,(2)$ eine analoge Ziffer (A) bilden: Ich empfehle GOP A 4668, Influenzaschnelltest, 330 Punkte, $€ 22,12,1,15$-fach. In der Summe ergeben sich insgesamt $€$ 38,20. Die punktemäßig

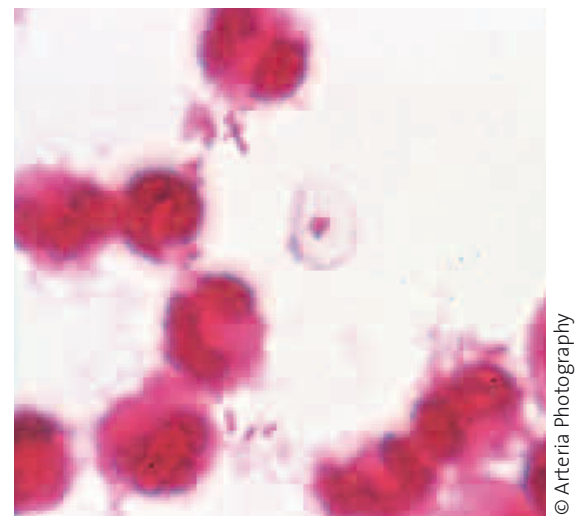

Hämophilus influenzae.

hohe analoge Position A 4668 ist sowohl aufgrund des Laboraufwandes als auch wegen der relativ hohen Materialkosten gerechtfertigt.

\section{Patient brauchte vorübergehend ein Sauerstoffgerät}

\section{Versorgerfirma holt das Gerät nicht mehr ab}

Dr. H. W., Allgemeinarzt, KV Bayern

Ein Patient, versichert bei der IKK, brauchte wegen vorübergehender Sauerstoffmangelversorgung ein Sauerstoffgerät. Jetzt ist er seit einigen Monaten nicht mehr sauerstoffpflichtig. Ich habe deshalb auch keine entsprechende Verordnung mehr ausgestellt. Die versorgende Firma verlangt nun über den Patienten von mir eine Bescheinigung, dass sie das Gerät abholen darf. Muss ich diesen Bürokratismus mitmachen?
Antwort: Ganz klar: Nein! Sie haben das oder die Geräte mit einem Hilfsmittelrezept für einen bestimmten Zeitraum verordnet. Für diesen Zeitraum muss die Firma für die Bereitstellung, Wartung und Ersatzlieferung zur Verfügung stehen. Die entsprechenden Kosten rechnet sie mit der Krankenkasse ab. Der Patient zahlt gegebenenfalls die vorgeschriebene Selbstbeteiligung. Die Krankenkasse schickt ihm eine Rechnung über die Höhe der Zuzahlung.
Mit Ablauf der Verordnung muss die Vertragsfirma ein Wiederholungsrezept anfordern. Erfolgt - wie in Ihrem Fall - keine Weiterverordnung, ist damit der Versorgungsvertrag beendet. Eine spezielle Bescheinigung für den Hilfsmittellieferanten ist vertraglich nicht vorgesehen. Sie haben Recht, wenn Sie diesen ausufernden Bürokratismus nicht mitmachen und diesen Vorgang kritisch hinterfragen. 